\title{
Clinical Trial Agreement
}

National Cancer Institute

\section{Source}

National Cancer Institute. Clinical Trial Agreement. NCI Thesaurus. Code C60777.

A legally binding document which governs the administrative/leg al terms under which a Study will be conducted. This includes rights regarding publication, confidential information, ownership, use of data, intellectual property, and indemnification. The Final Budget, which must be reviewed and approved by the Institution, and the Protocol are incorporated into the Clinical Trial Agreement. 